\title{
A Study on the Mechanism of Information Sharing between Customer Involvement and New Product Development
}

\author{
Xie Minglei ${ }^{1}$ \\ ${ }^{1}$ School of Business, Shandong University of Political Science and Law, Ji’nan, China
}

\begin{abstract}
Data from 275 questionnaires were used to examine the role of information-sharing customers in value creation of new products. The results show that information sharing plays a part in mediating the relationship between customer participation and new product performance, and the two dimensions of information sharing enhance the interaction of new product performance. The above conclusions answer the mechanism of information sharing in the process of customer's participation in the value creation of new products, reveal the interactive effect of "inside-out" and "inside-out" information sharing, and provide a reference for small and medium-sized enterprises (SMEs) in the manufacturing industry to participate in the development of new products.
\end{abstract}

\section{Introduction}

The customer's participation in the process of product innovation is considered as an important source of enterprise competitive advantage. At present, many enterprises actively invite customers to participate in the various stages of new product development. However, there is no consensus on the role of customer engagement in new product development. While most studies have found that customer engagement has a positive impact on new product development, some studies have come to the opposite conclusion. Translating different customer knowledge into innovative new products is not a simple process. It requires combining customer knowledge with the internal knowledge of the product development team to translate different inputs into innovative product design. In particular, small and medium-sized enterprises are difficult to effectively organize new product development activities due to lack of market information, know-how and other resources. However, there is little literature on the mechanisms by which customer engagement affects new product development.

From the perspective of RBV, information and knowledge from are important resources for the enterprise. In the process of new product development, exploration, experiment and improvisation through interaction with customers will make this important resource be used more timely and fully, which will create marketing and innovation differentiation, gain competitive advantages in the market and improve new product performance[1]. Information sharing is a self-reinforcing communication process, i. e. with the deepening of communication, the communication efficiency will continue to improve, and both parties will share more information at a higher level. Information sharing is divided into two dimensions according to the flow direction of information, namely "from inside out" and "from outside to inside", and the self-reinforcing process of information sharing can be verified by examining the interaction effect between them. Based on the above discussion, a theoretical model with information sharing as mediating variable is constructed (see figure 1). The theoretical basis of the research hypothesis is discussed below.

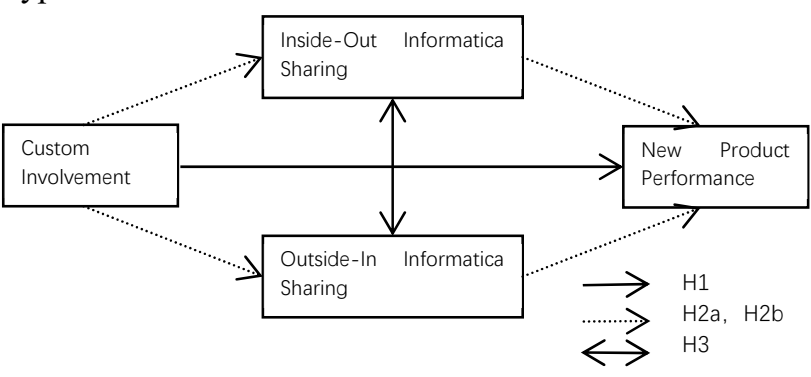

Fig1. Concept map of this study

\section{Theoretical basis and research hypothesis}

\subsection{Influence of customer involvement on new product performance}

Customer involvement refers to the process of customers participating in the company's new product development, i. e. customers share their needs, solutions and other knowledge in the process of new product development. Customer involvement enables enterprises and customers to form a clear understanding of future market demands, so as to make highly feasible plans to meet the needs and systematically coordinate relevant activities to complete tasks[2]. 
It is a complex process to transform new product design into products that can effectively meet customers' needs, which requires a deep understanding of customers' needs[3]. Extensive collaboration with customers can capture the voice of the market and help create effective user-oriented design[4]. Literature on the impact of customer involvement on the performance of new products mostly get positive results, but there is also evidence that different types of customer involvement in new product development will bring different results. The participation of "ordinary" customers in the development of new products will lead enterprises to pay too much attention to a single customer group, and the new products may not meet the needs of a wide range of customers, which will have a negative impact on the performance of new products. The "average" user's perception of a new product/service is limited by past experience and is unlikely to inspire new ideas, especially in fast-changing industries[5]. However, lead users have stronger and more advanced needs than other members in the target market, and they tend to provide "breakthrough" potential innovations for the target market. Existing studies have also shown that customers who have leading user characteristics participating in new product development could contributes to product diversity and novelty, and promotes the degree of customer acceptance of new products[6]. Leading users have two characteristics: (1) expect to obtain relatively high relevant benefits from the solution of specific requirements; (2) experience these needs earlier than most users in the market[5]. Business customs can experience new products at the earliest and hope to gain higher profits through new product development, which conforms to the characteristics of leading users. Their participation in new product development is conducive to improving the performance of new product development. In conclusion, the following hypothesis is proposed:

H1: Customer involvement can improve the performance of new products, that is, the higher the customer involvement, the better the performance of new products.

\subsection{Mediating role of information sharing}

Information sharing is one of the key business processes of integration between enterprises and customers, through which enterprises share information on technology, marketing, production and inventory with customers[7]. In the process of cooperative development of new products, each party should understand the relevant knowledge owned by the others, evaluate and identify the information to be Shared, so as to improve their cooperation efficiency. For enterprises, information sharing among partners can make transactions more stable and reduce market uncertainty. In the long run, customers' preferences and demand for new products are in constant change. Customer involvement helps enterprises grasp the vertical changing customer demand information. Continuous information sharing can help enterprises to explore and understand how the needs of customers is evolved and iterated, which can help enterprise find better opportunities to create value for customs and obtain unique ability for competition advantage.

For customers, sharing information about cost structure, production and engineering characteristics with customers can help them manage budget constraints effectively and make appropriate adjustments to new product preferences. Customer participating in enterprise's new product development can get a lot of information about the new product features and experience, and spread outward through various channels, that will help other adopters understanding and adoption of new products, promote the number of adopters to "critical mass" at an early date, entered the stage of rapid diffusion. In conclusion, the following hypothesis is proposed:

$\mathrm{H} 2$ : information sharing plays an intermediary role in the relationship between customer involvement and new product performance.

H2a: "inside-out" information sharing plays an intermediary role in the relationship between customer involvement and new product performance.

$\mathrm{H} 2 \mathrm{~b}$ : "outside-in" information sharing plays an intermediary role in the relationship between customer involvement and the performance of new products.

\subsection{Interaction effects of "inside-out" and "outside-in" information sharing.}

When customers participate in the development of new products, information sharing between enterprises and customers about demand preferences is the key premise to create new product value[8]. Customers can generate creative ideas for new products by explicitly expressing their unmet needs and can design new products with manufacturers to meet these needs[9]. In return, enterprises will return more information about cost structure, production and engineering characteristics to customers while promoting new product development, which will help customers to effectively manage budget constraints and make appropriate adjustments to new product preferences. On the other hand, if business owners share new product information with customers, customers may generate more new ideas or better express their potential needs based on the new information, which will help enterprises to develop products that can better meet market needs. According to social exchange theory, the most satisfying social relationship is the fair one: people don't like to be exploited by others, and they usually don't want to take advantage of others, too. When enterprises share information with customers, if one party actively shares more information with the other party, it will promote the other party to actively share more effective information. In conclusion, the following hypothesis is proposed:

H3: "inside-out" and "outside-in" information flow have positive interaction effects on new product performance.

\section{Research methods}

In accordance with the method of random sampling, questionnaires were distributed to senior managers of 
small and medium-sized manufacturing enterprises with overseas operations. The companies are from Jiangsu province in China's Yangtze river delta region and Guangdong province in the pearl river delta region. Two recycling rounds were distributed between March and August in 2018. In the first round, 210 questionnaires were collected, and 45 questionnaires with incomplete information and inconsistent filling were removed. In the second round, 140 questionnaires were collected, and 30 questionnaires with more data gaps were eliminated. A total of 275 valid samples were collected from the two questionnaires.

In order to ensure the reliability and validity of the measurement tools, the scale used in the research is mainly the mature scale in domestic and foreign literature. Likert grade 7 score was used for evaluation, indicating the degree of acceptance of the respondents to the measurement items from 1-7: 1 is "strongly opposed", 7 is "strongly agreed".

Dependent variable. The scale of Acur et al.[10] is used to measure the new product development, which consists of four items. After the confirmatory factor analysis, an insignificant item was deleted, and finally three items were used as the measurement scale of new product development.

Independent variables. Customer involvement. Referring to the research results of scholars such as Chen \& Paulraj[11], the measurement of customer involvement is mainly based on the perspective of customer involvement in new product development, including three measurement items.

Mediating variables. Drawing research results of Cai et al.[12], considering the two-way information flow characteristics, from "from the inside out" and "from inner to outer in an" information sharing two dimension measurement, namely, our company with main customers to share information and share information of our major customers and the company, each dimension includes three item.

Control variables. According to the existing research results, some factors at the enterprise level will affect the performance of new products. Using enterprise size and age as control variables, the measurement method of enterprise size is the natural logarithm of sales volume, and the measurement method of enterprise age is the length of time from enterprise registration to 2017. In the relevant research, it is pointed out that SMEs will pay more attention to product innovation in order to gain competitiveness in export, so competitiveness is also taken as a control variable in the model.

Cronbach's Alpha was used to measure the reliability of the questionnaire. The test results showed that the Cronbach's Alpha coefficient of our main customers sharing information with the company was 0.698 , higher than the limit level of 0.60 .

\section{Data analysis}

\subsection{Descriptive statistics, Correlation analysis and $T$ test}

The descriptive statistical results of variables showed that the main variables of new product performance, customer involvement, information sharing between our main customers and the company, and the average information sharing between our company and the main customers are $5.624,5.141,5.376$ and 5.313 respectively, which indicates that the degree of customer involvement is relatively high in the process of new product development.

The Pearson (lower triangle) and Spearman (upper triangle) correlation table of major variables showed that the independent variable of customer involvement in new product development is significantly positively correlated in Pearson and Spearman tests, indicating that the higher the degree of customer involvement is, the better the new product performance will be. There is a significant positive correlation between the information Shared by our customers and our company and our major customers and the performance of new products, indicating that information sharing has an important impact on the performance of new products.

We compared the mean differences of variables with different type of enterprises (private and non-private enterprises) and customer involvement ways. The test results show that in the first classification comparison, the performance of new product development in the private group is lower than that of other groups, and there is no significant difference in the three variables of customer involvement, our attention to customer sharing information with the company, and our company sharing information with major customers.

\subsection{Hypothesis test}

Table 1 shows the test results of customer involvement in influencing the performance of new products through information sharing and the interaction effect of information sharing on the performance of new products. Among them, model 1 is the direct effect of independent variable customer involvement (CI) on new product performance (NPP). The results show that customer involvement $(\mathrm{CI})$ has a significant impact on new product performance (NPP), that is, more customer involvement (CI) is more conducive to the improvement of new product performance (NPP). Hypothesis 1 is verified. Model 2 and model 3 is customer involvement by variable share information of our major customers and the company (ISC) on new product performance test (NPP) of the indirect effect, model 2 shows that customer involvement (CI) of mediation variables (ISC) has significant positive effect, namely the more customers to participate in our customer to share information with the company, the more the model show that customer involvement $(\mathrm{CI})$, mediation variables (ISC) on new product performance (NPP) still has significant positive effect, but the customer involvement (CI) estimated coefficient value decreased obviously. The model 4 and 5 are customer involvement variables (CI) by our company and customers to share information (ISF) on new product performance test (NPP) of the indirect effect, model 4 indicates that customer involvement (CI) of mediation variables (ISF) has significant positive effect, namely the more customers to 
participate in our company when sharing information with main customers, the more the model 5 shows that customer involvement (CI), mediation variables (ISF) on new product performance (NPP) still has significant positive effect, but the customer involvement (CI) estimated coefficient value decreased obviously. The test results of model 1-5 show that our main customers share information with the company (ISC) and our company share information with the company (ISF) play a partial intermediary role between customer involvement and new product performance, that is, hypothesis 2 is verified. Model 6 is a test of the influence of the interaction between our main customers and the company sharing information (ISC) and our company sharing information (ISF) on the performance of new products. In order to avoid the multicollinearity problem, the two variables are centralized. The results show that the interaction effect of the two mediating variables has a significant positive effect on the performance of new products, that is, our main customers share information with the company (ISC) and our company share information with the company (ISF) have an interdependent relationship on the performance improvement of new products, and hypothesis 3 is verified.

Table1. Mediating and interacting effect test

\begin{tabular}{|c|c|c|c|c|c|c|}
\hline & model (1) & model (2) & model (3) & model (4) & model (5) & model (6) \\
\hline & NPP & ISC & NPP & ISF & NPP & NPP \\
\hline firmage & -0.158 & 0.118 & -0.188 & -0.011 & -0.154 & -0.171 \\
\hline & $(0.123)$ & $(0.139)$ & $(0.119)$ & $(0.108)$ & $(0.116)$ & $(0.117)$ \\
\hline sale_1 & 0.018 & 0.028 & 0.011 & 0.033 & 0.009 & 0.004 \\
\hline & $(0.022)$ & $(0.027)$ & $(0.021)$ & $(0.024)$ & $(0.020)$ & $(0.021)$ \\
\hline $\mathrm{CI}$ & $0.274 * * *$ & $0.385 * * *$ & $0.174 * * *$ & $0.461 * * *$ & $0.139 * *$ & \\
\hline & $(0.057)$ & $(0.049)$ & $(0.067)$ & $(0.046)$ & $(0.062)$ & \\
\hline ISC & & & $0.258 * * *$ & & & $0.233 * *$ \\
\hline & & & $(0.090)$ & & & $(0.090)$ \\
\hline ISF & & & & & $0.291 * * *$ & $0.293 * * *$ \\
\hline & & & & & $(0.089)$ & $(0.087)$ \\
\hline ISC*ISF & & & & & & $0.110^{*}$ \\
\hline & & & & & & $(0.066)$ \\
\hline Constant & $3.652 * * *$ & $2.103 * * *$ & $3.109^{* * *}$ & $2.240 * * *$ & $3.000 * * *$ & $2.497 * * *$ \\
\hline & $(0.459)$ & $(0.346)$ & $(0.467)$ & $(0.405)$ & $(0.530)$ & $(0.464)$ \\
\hline $\begin{array}{c}\text { Observation } \\
\mathrm{s}\end{array}$ & 274 & 274 & 274 & 274 & 274 & 274 \\
\hline Adjusted $\mathrm{R}^{2}$ & 0.168 & 0.316 & 0.212 & 0.371 & 0.218 & 0.240 \\
\hline F-test & 12.846 & 33.484 & 15.351 & 35.587 & 11.998 & 15.627 \\
\hline Prob $>F$ & 0.000 & 0.000 & 0.000 & 0.000 & 0.000 & 0.000 \\
\hline
\end{tabular}

\subsection{Sobel-goodman intermediary test}

On the basis of the above analysis, the significance of mediating effect is further tested by Sobel - Goodman method. The significance test of mediating effect includes: Sobel test, Goodman 1 test and Goodman 2 test, and the software automatically generates the test results of three statistics. The test results show that the Sobel, Goodman1 and Goodman2 tests of our main customers sharing information with the company (ISC) and our company sharing information with the company (ISF) are significant, that is, the hypothesis is supported. Among them, the proportion of intermediary effect between our main customers and the company sharing information (ISC) and our company sharing information with the company (ISF) is $36.4 \%$ and $49.1 \%$ respectively.

\section{Conclusions and implications}

Based on the above results, three conclusions can be drawn: (1) customer involvement can effectively promote the performance of new product development. (2) Information sharing plays a key intermediary role in the process of customer involvement in promoting the performance of new products. (3) Information sharing is a self-reinforcing communication process. With the deepening of information sharing between enterprises and customers, communication efficiency will continue to improve and both sides will share more information at a higher level.

The above conclusions answer the mechanism of information sharing in customer involvement in new product value creation, and reveal the interactive effects of "inside-out" and "outside-in" information sharing. At present, China is in a critical period of transformation from a manufacturing power to a manufacturing power. However, for SMEs, due to the lack of resources, it is often difficult to promote their innovation or activities. The conclusion provides a new understanding for small and medium-sized manufacturing enterprises to make full use of internal and external resources to develop new products. Enterprises can attract customers to participate in the development of new products, better use of market resources, improve innovation ability. Enterprises can 
effectively share information with customers, promote the full use of customer resources, and promote the efficiency of new product development.

\section{References}

1. B. Menguc, S. Auh, P. Yannopoulos. Customer and Supplier Involvement in Design: The Moderating Role of Incremental and Radical Innovation Capability[J].Journal of Product Innovation Management,2014,31(2):313-328.

2. M. Barratt Understanding the Meaning of Collaboration in the Supply Chain[J]. Supp Chain Mnagmnt,2004,9(1):30-42.

3. M. Crawford, B.A. Di.New Products management[M].Boston:MA: McGraw-Hill Irwin,2011.

4. W. Veryzer R, \& Borja De Mozota B. The Impact of User - oriented Design on New Product Development: an Examination of Fundamental Relationships*[J].Journal of Product Innovation Management,2005,22(2):128-143.

5. E.A. Von hippel. Sources of Innovation[M].NY:Oxford University Press, 1988.

6. D. Mahr, Lievens A, \& V. Blazevic. The Value of Customer Co-created Knowledge During the Innovation Process[J].Journal of Product Innovation Management,2014,31(3):599.

7. A. Lau, E. Tang, \& C. M. Yam. Effects of Supplier and Customer Integration on Product Innovation and Performance: Empirical Evidence in Hong Kong Manufacturers[J].Journal of Product Innovation Management,2010,27(5):761-777.

8. R. Cooper, \& E. Kleinschmidt. Benchmarking the Firm's Critical Success Factors in New Product Development[J].Journal of Product Innovation Management,2010,12(5):374-391.

9. E. Von hippel. Democratizing Innovation[M].Cambridge, MA: MIT Press,2005.

10. N. Acur, D. Kandemir, \& H. Boer.Strategic Alignment and New Product Development: Drivers and Performance Effects[J].Journal of Product Innovation Management,2012,29(2):304-318.

11. I. J. Chen, \& A. Paulraj. Towards a Theory of Supply Chain Management: the Constructs and Measurements[J].Journal of Operations Management,2004,22(2):119-150.

12. S. Cai, M. Jun \& Z.Yang. Implementing Supply Chain Information Integration in China: the Role of Institutional Forces and Trust[J].Journal of Operations Management,2010,28(3):257-268. 